\title{
Prospects of diversification and ensuring energy safety of Uzbekistan
}

\author{
Kahraman Allaev ${ }^{1}$, Tokhir Makhmudov ${ }^{1 *}$ \\ 1 Tashkent State Technical University named after Islam Karimov, Power plants, networks and systems Department, Universitetskaya 2 , \\ Tashkent, Uzbekistan
}

\begin{abstract}
The data on the current state of energy in Uzbekistan are given. The need to diversify the structure of the energy balance of the republic is shown, which ensures the energy security of the state in the medium and long term. It is argued that the construction of a nuclear power plant in Uzbekistan is not only expedient, but also necessary. In the future, renewable energy and nuclear power plants will become the basis of energy in Uzbekistan.
\end{abstract}

\section{Introduction}

The global energy transformation currently taking place in the world in the 21 st century will have an impact on the technological, social, economic and other directions in the development of countries. The emerging new reality will be fundamentally different from the usual energy geopolitics, which has dominated for more than a hundred years [1-6].

Fossil fuels being the basis of the global energy system, economic growth and modern lifestyles, over the past two centuries of operation have increased the global use of energy fifty times, creating an environment in the modern world [1]. The geographical concentration of fossil fuels has had a significant impact on the welfare and security of nations. At present, one can observe the emerging energy of the future, which can be represented in the form of a square, the sides of which are the sun, wind, hydropower and atomic energy. Such a transformation of the energy sector can lead to as radical changes in its scale and impact as the industrial and agricultural revolution. The Republic of Uzbekistan is subject to such changes.

The Republic of Uzbekistan is a dynamically developing state located in the central part of Central Asia. It has common borders with Kazakhstan (2203 $\mathrm{km})$, Turkmenistan $(1621 \mathrm{~km})$, Tajikistan $(1161 \mathrm{~km})$, Kyrgyzstan (1099 km), Afghanistan (137 km) [7].

The territory of Uzbekistan is $447000 \mathrm{~km}^{2}$, of which $22000 \mathrm{~km}^{2}$ is water. The Aral Sea (in 1998, the surface area was $28687 \mathrm{~km}^{2}$ ) is located in the north-west of the country. The rivers of Uzbekistan are part of the Aral Sea basin, which is fed by two main rivers: the Amu Darya (length of $2580 \mathrm{~km}$ ) and the Syr Darya (length of $2221 \mathrm{~km})$.

The fuel and energy complex of the Republic of Uzbekistan is the largest association of enterprises in Central Asia for the extraction, processing, transportation of oil, natural gas, coal, as well as the production and distribution of electrical and thermal energy.

By the measures taken by the leadership of the country, Uzbekistan in 1995 achieved energy independence. At present, taking into account the selfsufficiency of the republic, measures are being taken for the medium and long-term satisfaction of its needs with the necessary high-quality energy resources based on the sustainable development of the industry.

Uzbekistan has concentrated about $50 \%$ of the generating capacity of the countries of Central Asia, which is more than 13 million $\mathrm{kW}$ of installed capacity, with the possibility of generating electricity of about 70 billion $\mathrm{kWh}$ per year. The Uzbek power system is the main link in the unbroken chain of production and transmission of electrical energy in the region. Geographical location, the presence of developed electrical networks allow you to successfully organize and be an active participant in the market of electrical energy and power [7].

The basis of the Uzbek energy system consists of large thermal power plants: Syrdarya thermal power station (TPP) (with a capacity of $3000 \mathrm{MW}$ ), Tashkent TPP (1860 MW), Novo-Angren TPP (2100 MW), Navoi TPP (1250 MW). 137 power units with unit capacity from 150 to $300 \mathrm{MW}$ are installed on them. The 800 MW power unit was commissioned at the Talimarjan thermal power plant.

The electric grid economy includes more than 230 thousand $\mathrm{km}$ of high voltage power lines and transformer substations with a total capacity of about 45 million kVA.

Electricity generation in Uzbekistan in the years 2000-2018, on average annually amounted to 50-67 billion $\mathrm{kWh}$. In 2018, more than 60 billion $\mathrm{m}^{3}$ of natural gas, about 3 million tons of petroleum products were

\footnotetext{
*orresponding author: tox-05@yandex.com
} 
produced, and coal production increased to 3.5 million tons.

\section{Development perspective}

The energy strategy of Uzbekistan sets the goal of ensuring energy independence and security, increasing energy efficiency, and reducing the impact of energy on the environment. To solve these problems requires the development and introduction of new technologies based on scientific advances that provide a safer, cleaner energy [8].

In the long term, Uzbekistan's energy sector has been tasked with increasing its electricity generation to 117 billion kWh by 2030 .

The implementation of this ambitious task will be carried out in the following directions [6]:

1. Intensification of energy efficiency and energy saving (reserve up to $40 \%$ of energy savings). This will require accelerated modernization of the main means of production, diversification of energy sources, conducting an efficient energy-saving policy, assessing the real costs of energy supply in the country, etc.

2. The widespread introduction of combined-cycle technologies instead of steam at thermal power plants will increase the efficiency of the units from $32 \div 35 \%$ to $54 \div 60 \%$ and, accordingly, will make it possible by 2030 to use as much natural gas for energy purposes as and now.

3. The development of energy resources of wind and sun. In most countries of the world, great work is being done to diversify the energy structure, including by expanding the use of non-carbon renewable energy sources and atomic energy $[1,2]$. According to estimates of domestic and foreign experts, the real technical potential of solar and wind energy in Uzbekistan is at least 10 million $\mathrm{kW}$ of power in each area.

4. Increasing the share of coal and shale in power generation using modern technologies for burning lowgrade solid fuels. The reserves of brown coal in Uzbekistan are about 2 billion tons, and shale about 50 billion tons. At the same time it is important to comply with the highest environmental standards.

5. Introduction of hydropower and hydroaccumulation stations, flexible tariff system, as well as closer cooperation with the power systems of neighboring countries - to give the system more flexibility, leveling consumption schedules during peak hours (maximum).

6. Studying the possibility of building nuclear power plants by 2030 and beyond. Solving this problem in the medium and long term is the content of the reform, development and implementation of the strategy for the development of the energy sector of Uzbekistan, taking into account the preservation of its export potential.

Currently, when generating electricity, natural gas dominates in the energy balance of Uzbekistan - its use reaches $90 \%$, i.e. there is a disproportion in the use of primary energy sources. In order to diversify the government of Uzbekistan expands the composition and base of energy resources. Consider the fuel base of the energy complex of Uzbekistan.

\section{Oil and gas industry}

The modern oil and gas industry of Uzbekistan is one of the largest sectors of the economy, the most important energy base of the country. The industry has created significant scientific and technical potential [14].

A large-scale action program has been developed for the intensive development of the oil and gas complex based on the use of high-quality equipment, materials, modern technologies, accelerating the pace of updating and replacing outdated equipment, implementing largescale projects with foreign companies and solving a range of social problems. The development of this program will allow Uzbekistan to significantly strengthen its fuel and energy independence and expand its integration into the world economy.

Uzbekistan is ranked 8th in the world in gas production. In the period from 1991 to 2018, the oil and gas industry of Uzbekistan showed extremely successful development rates in all production, technical and economic indicators. By 2019, hydrocarbon production reached 60 million tonnes of oil equivalent (toe), which is more than 1.6 times more than that produced in 1991 [9].

The processing industry of hydrocarbon raw materials of Uzbekistan is successfully developing. The modern Bukhara and Fergana and other refineries are working effectively. Shurtan (2001), Ustyurt Gas Chemical Complexes (2016), Kandym Gas Processing Complex (2018) are industrial giants working on the basis of modern oil and gas processing technologies.

\section{Coal industry}

According to experts, in Uzbekistan the estimated resource of coal is more than 2 billion tons [7]. Industrial stocks amount to 1.9 billion tons, of which brown 1.853 million tons, stone -47 million tons.

It is planned to intensify coal mining, with the result that its annual volume should increase to 20 million tons by 2025 , of which brown coal - to 9.200 million tons, hard coal - to 110 thousand tons (Fig. 1).

Currently, coal mining is carried out in three fields: Angren (Tashkent region), Baysun and Shargun (Surkhandarya region). There are still a number of coal fields in the republic, for example, the Terekli site in the Kashkadarya region with industrial reserves of 50 million tons. 


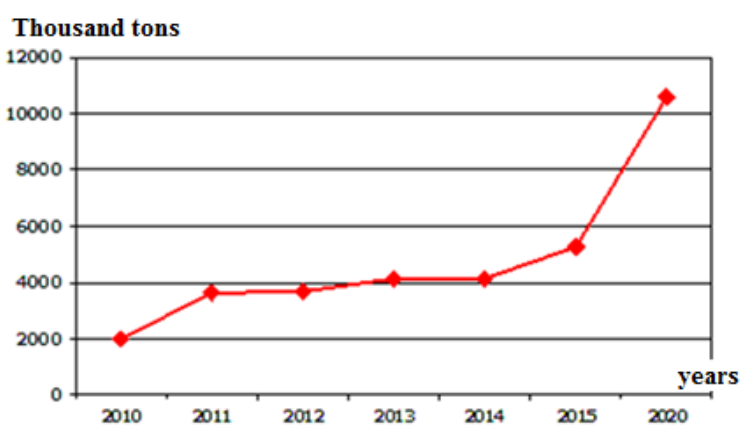

Fig. 1. Prospects for increasing coal production in Uzbekistan.

On the basis of the Angrenskoye deposit, coal is processed by the method of underground gasification of coal - by the Podzemgaz station (OJSC Erostigaz), commissioned in 1961 and still remaining one of the largest and unique facilities of its kind in the CIS. The design capacity of the station is 2.3 billion $\mathrm{m}^{3}$ of gas per year or in terms of coal - 0.6 million tons.

Coal is used in the country for the development of motor fuel, calcium carbide, sorbents, activated coal and medicines. Coal from the Shargunskoye deposit is used as carbonaceous additives in ferrous and non-ferrous metallurgy, as well as coke briquettes at Uzmetkombinat, which reduces the volume of coke imports for foundry.

In the future, the issue of using oil shale is pending. The territory of Uzbekistan is rich in oil shale, with a specific heat of combustion of more than $1200 \mathrm{kcal} / \mathrm{kg}$. Technically realizable forecast resources of the Kyzylkum and Amudarya combustible basins amount to 2 billion tons, and total geological reserves of 47 billion tons.

\section{Electricity}

The power industry of Uzbekistan is a basic sector of the economy of the Republic and, having a significant production and scientific and technical potential, has a significant impact on its development. Uzbekistan has become the largest energy power in the Central Asian region.

Over the past 30 years, electricity production in the country has increased by more than 3 times, with the possibility of generating electricity to $55-70$ billion $\mathrm{kWh}$. (Fig.2).

According to the CIS Electric Power Council, the total installed capacity of power plants in Uzbekistan at the end of 2017 was $14140 \mathrm{MW}$, including $12129 \mathrm{MW}$ the capacity of thermal power plants (85\%) 1878.7 MW - hydroelectric power plants (13\%), 133 MW - other (2\%) [10].

The total length of electrical networks exceeds 235 thousand $\mathrm{km}$, including the main transmission lines of 220 and $500 \mathrm{kV}-7.8$ thousand $\mathrm{km}$.

Currently in Uzbekistan, $83 \%$ of electricity is generated by gas, $13 \%$ by hydroelectric power plants, $4 \%$ by coal.

In Uzbekistan, about 16 billion $\mathrm{m}^{3}$ of natural gas, 85 thousand tons of fuel oil and 2.3 million tons of coal are consumed annually for the needs of the power industry $[11,12]$.

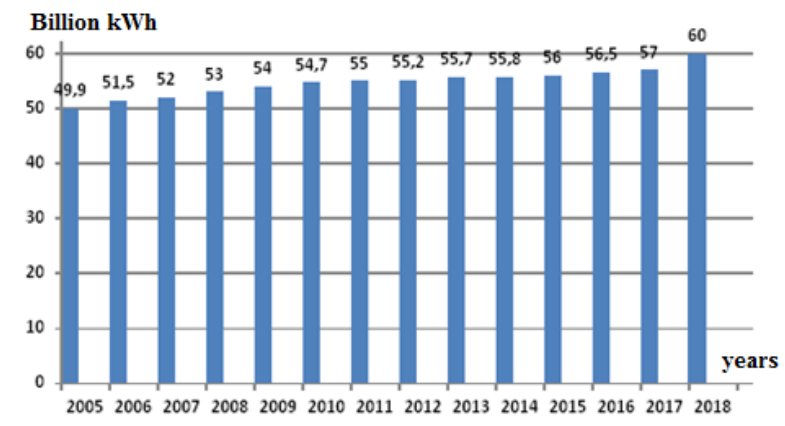

Fig. 2. Electricity production in Uzbekistan.

The problem of aging of fixed assets in power system, which is the basis of the Uzbek energy system, is most acute. 63 turbine generators with a unit capacity of 25 to $800 \mathrm{MW}$ are installed at thermal power plants in Uzbekistan, of which 39 turbines with a capacity of 5.9 million $\mathrm{kW}$ (or 55\%) have been in operation for more than 30 years.

Electricity generation at hydropower plants of Uzbekistan is more than 6.5 billion $\mathrm{kWh}$ per year. After the reconstruction and construction of new stations, the power generation will exceed 9 billion $\mathrm{kWh}$. There is also the problem of aging equipment: 63 out of 69 hydraulic turbines were installed more than 30 years ago. As the world and domestic experience shows, the problem of increasing the energy efficiency of the production and consumption of electricity in the long term is solved in stages, through modernization, reconstruction, renovation of power and power grid equipment $[1,11]$.

The need to improve the energy efficiency of the power industry requires the introduction of the next level of automated information and measurement systems for the commercial accounting of electricity generation and consumption.

The power industry of Uzbekistan has begun reforming. By the decision of the President of the Republic of Uzbekistan dated March 27, 2019, the Ministry of Energy of Uzbekistan was established on the basis of state energy monopolies - Uzbekenergo JSC and Uzbekneftegaz JSC, Uzgidroenergo JSC, Ugol JSC, Uzatom Agency. Three joint-stock companies were organized: Thermal Power Plants, National Electric Networks of Uzbekistan, and Regional Electric Networks. The first will be responsible for the production of electric energy, the second - for transportation between regions and interaction with neighboring energy systems, and the third joint-stock company will sell electricity to end users.

The adopted document is aimed at developing not only the electric power industry, but the entire economy of Uzbekistan as a whole.

\section{Potential of renewable energy sources (RES) of Uzbekistan}


The reserves of renewable energy in the Republic of Uzbekistan are huge: the total volume (hydro, solar, wind, geothermal, biomass) is about 118 billion toe. Of these, only 179 million toe are economically viable, and currently only $0.31 \%$ of this potential has been developed.

The energy of the Sun, falling per square meter of the surface of the territory of the Republic, is in the range of $1500-1900 \mathrm{kWh} / \mathrm{m}^{2}$, which is equivalent to 0.154 toe. If we consider that in the republic the number of sunny days is more than 250 , then this is a large reserve.

Solar and wind energy can be the main driving force of the economy and the energy production sector in Uzbekistan. Under the optimistic scenario, the installed capacity of solar power plants can reach $10 \mathrm{GW}$ by 2031, which will produce $17 \mathrm{TWh}$ of energy, providing an annual income of about 1.8 billion dollars and create up to 36 thousand jobs.

Regions with average wind speeds of at least $4-8 \mathrm{~m} /$ $\mathrm{s}$ are located in the Aral Sea region, Navoi and Tashkent regions. According to experts, taking into account the rapidly developing equipment and technologies, the practically realizable potential of wind energy in Uzbekistan is at least $10 \mathrm{GW}$.

The development of hydropower in the republic will go at the expense of realizing the potential of small rivers, irrigation canals, reservoirs, watercourses.

Uzbekistan has significant geothermal and petrothermal resources. The explored reserves of hydrothermal resources with a temperature of $40-120{ }^{\circ} \mathrm{C}$ are $16 \cdot 10^{3}$ toe / year, and the forecasted reserves are much higher. Petrothermal resources (heat contained in dry heated rocks occurring at a depth of up to $3 \mathrm{~km}$ ) are estimated to be about $6.7 \cdot 10^{12}$ toe.

In addition, in Uzbekistan there are more than 260 large landfills with a total average annual accumulation of more than 7 million tons. Up to $250 \mathrm{~m}^{3}$ of gas can be obtained from each ton of waste, which is approximately 1.5 billion $\mathrm{m}^{3}$ of gas per year with its further use for the production of heat and electricity.

\section{Nuclear power engineering of Uzbekistan}

Nuclear power engineering is among the fastest growing areas in the world, as significant progress has been made by scientists in improving the safety of a new generation nuclear power plants (NPP) [2].

To date, 193 nuclear power plants with 454 power units are operated in 32 countries. Another 56 power units are under construction.

On December 29, 2017, Uzbekistan signed an intergovernmental agreement on cooperation in the field of peaceful uses of atomic energy with Russia [11-13]. In July 2018, the President of the Republic of Uzbekistan signed the Decree "On measures for the development of nuclear energy in the Republic of Uzbekistan".

It is obvious that the world reserves of economically and environmentally acceptable fossil hydrocarbons are limited, and in this case, nuclear energy, along with renewable energy sources, becomes an example of a carbon-free alternative to fossil energy resources [1, 5].

A modern NPP is a high-tech construction, hightech-logical equipment and highly qualified personnel. That is, nuclear energy will give impetus to the development of science, education and the emergence of new professions.

In Uzbekistan, a nuclear power plant will be built as part of two power units with VVER reactors with a capacity of $1200 \mathrm{MW}$ each. These are new generation units, so-called. " $3+$ " generations, which differ from their predecessors by a high degree of reliability, simplicity in management due to the complete automation of the entire production cycle. At the same time, there is no negative impact on the environment, the design of the reactor has a high degree of seismological stability and takes into account all the IAEA safety requirements [11-13].

The planned construction of a nuclear power plant in Uzbekistan will ensure a stable supply of electricity in the country. This will be facilitated by a signed memorandum of cooperation between the Russian State Corporation Rosatom and the Academy of Sciences of Uzbekistan [11].

The introduction of atomic energy minimizes carbon dioxide emissions into the atmosphere, which is the main component of greenhouse gases that affect climate change.

Nuclear power plays a key role in ensuring the implementation of the Paris Climate Agreement, signed by Uzbekistan on April 19, 2017, under which it was decided to take measures to prevent temperature changes by more than $1.50{ }^{\circ} \mathrm{C}$. Uzbekistan has acceded to the Convention on the Safety of Spent Fuel Management and the Safety of Radioactive Waste Management and the Agreement on the Basic Principles of Cooperation in the Field of Peaceful Use of Atomic Energy [11-13].

The project for the construction of nuclear power plants in Uzbekistan is estimated at about $\$ 13$ billion, of which $\$ 11.3$ billion is provided by Russia as a state export credit [12].

The Republic of uranium reserves is on the 11th place in the world (131 thousand tons) and mined uranium is sold primarily in the United States, China and Korea [13].

\section{Conclusion}

The construction of a nuclear power plant will give a serious impetus to the development of energy, science, education and nuclear medicine in the country. Therefore, this is a serious leap in the development of the national economy and the development of national personnel. This is an opportunity to develop energyintensive sectors of the economy in the country, while preserving the environment without having a harmful effect, because Atomic energy is a source of clean energy. Therefore, the construction of nuclear power plants in Uzbekistan is not only justified, but also extremely necessary! 
The full-fledged operation of a nuclear power plant will make it possible to save 3.7 billion $\mathrm{m}^{3}$ of natural gas annually. As a result of its processing, petrochemical products with high added value will be produced. If the saved gas, even without processing, is sent abroad for export, it will already provide the republic with an additional 550-600 million dollars a year [12].

In general, about nine thousand people will be employed in the construction of the nuclear power plant, and after commissioning, 3.5 thousand people, while engineering and technical workers of the highest qualification will be involved.

Consequently, nuclear and renewable energy combined with the development of energy storage systems is transformed into a force that creates a new, clean energy future in the world $[1,6]$. In the second half of the 21 st century, they will become the dominant factor in ensuring the energy balance in the world and in Uzbekistan.

According to the authors forecast, by 2030, as a result of the implementation of the measures planned, the following diversified structure of electricity generation should be expected: gas-47\%, NPP-18\%, hydro-electric power plants (HPP) - 10\%, coal - 12\%, renewable energy sources - 13\% (Fig. 3 .) to ensure the energy security of the state and the growth of the investment attractiveness of the domestic power industry.

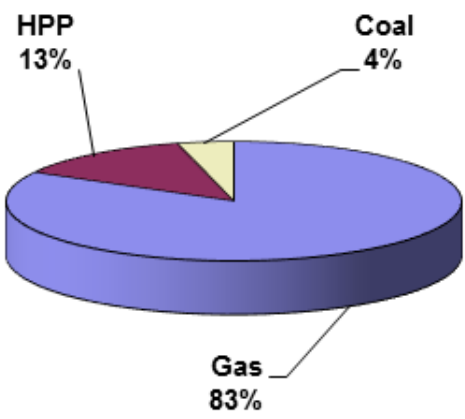

A

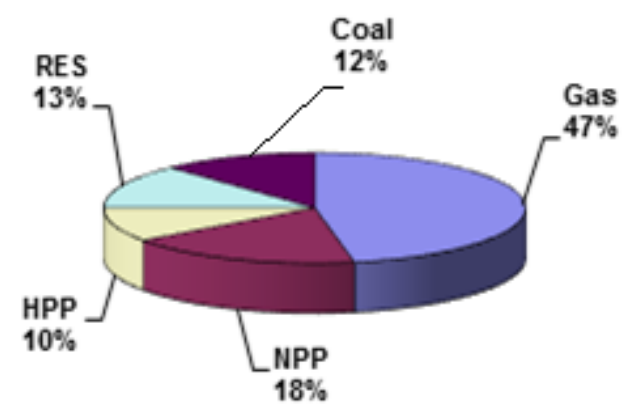

B

Fig. 3. Power generation in Uzbekistan: A - 2017, production of 57 billion $\mathrm{kWh}$.

B - 2035, production of 117 billion $\mathrm{kWh}$ (the forecast of the authors).

Thus, large-scale work carried out in the energy sector of Uzbekistan on the development of the fuel and energy complex will, in the future, make it possible to significantly diversify its structure, which will strengthen one of the most important indicators - the energy security of the republic.

\section{References}

1. A New World: The Geopolitics of the Energy Transformation, 88 p. (2019).

URL: https://www.irena.org/publications/2019/Jan/ANew-World-The-Geopolitics-of-the-Energy-

Transformation

2. J. Buongiorno, J. Parsons, M. Corradini, D. Petti, The future of nuclear energy in a carbon-constrained world. An interdisciplinary MIT study, 248 p. (2018).

URL:https:/www.ourenergypolicy.org/wp-content/ uploads /2018/09/The-Future-of-Nuclear-Energy-in-aCarbon-Constrained-World.pdf

3. M. Alverà, David C. Carroll, I. Marten, Global gas report 2018, 60 p. (2018).

URL:http://www.snam.it/export/sites/snam-rp/ repository/file/gas_naturale/global-gas-report/ global_gas_report_2018.pdf

4. Jan Ban, Jorge León Arellano, Haris Aliefendic and others. World Oil Outlook 2040, 412 p. (2017)

URL: https://www.opec.org/opec_web/flipbook/ WOO2017/WOO2017/assets/common/downloads/WO O\%202017.pdf

5. World Energy Council. World Energy. Issues Monitor, 211 p. (2019).

URL: https://www.worldenergy.org/ publications/ 2019/world-energy-issues-monitor-2019-managing-thegrand-energy-transition/

6. J. Pyper, Fossil Fuels Won't Go Away, Even if the Energy Transition Accelerates (2018).

URL: https://www.greentechmedia.com/articles/read/ woodmac-fossil-fuels-wont-go-away-acceleratedenergy-transition\#gs.m6c8um

7. K.R. Allaev, Energy of the World and Uzbekistan. Tashkent: Molia, 388 p. (2007)

8. K.R. Allaev, Energy needs a strategy. Economic Review, 6, 40-47 (2018)

9. The main indicators of Uzbekneftegaz (2019).

URL: http://www.ung.uz/investors-and-shareholders/ information-disclosure/activities/

10. List of power plants in Uzbekistan.

URL: https://ru.wikipedia.org/wiki.

11. M. Djangirov, An expert from Uzbekistan on the safety of nuclear power plants for the region (2018). URL:https://nuz.uz/intervyu/35771-ekspert-izuzbekistana-o-bezopasnost i-aes-dlya-regiona.html 12. A.M. Xodjaev, Does NPP need Uzbekistan? (2018). URL: https://nuz.uz/kolumnisty/34567-nuzhna-li-aesuzbekistanu.html

13. M. Djangirov, Atomic Renaissance. What will give Uzbekistan entry to the nuclear club? (2018). URL: https://nuz.uz/nauka-i-tehnika/33844-atomnyyrenessans-chto-dast-uzbekistanu-vstuplenie-v-yadernyyklub.html

14. A.A. Abidov, P.K. Azimov, To the problem of increasing oil production in Uzbekistan. Oil and gas, 1, 11-14. (2003) 